\title{
Implementation and outcomes of a responsibility-based continuing professional development protocol in physical education
}

By: Michael A. Hemphill, Thomas J. Templin, and Paul M. Wright

Hemphill, M. A., Templin, T. J. \& Wright, P. M. (2015). Implementation and outcomes of a responsibility-based continuing professional development protocol in physical education. Sport, Education and Society, 20(3), 398-419.

This is an Accepted Manuscript of an article published by Taylor \& Francis in Sport, Education and Society in April 2015, available online:

http://www.tandfonline.com/10.1080/13573322.2012.761966

\begin{abstract}
:
Research in education and physical education has emphasized the need for continuing professional development (CPD) programs that are aligned with best practices. More specifically, scholars interested in teaching personal and social responsibility (TPSR) have emphasized the need to examine teachers' CPD. The purpose of this study was to provide a novel responsibility-based CPD experience to three physical educators and examine its impact on a middle school physical education program in the USA. Data were collected through systematic observations, interviews, nonparticipant observations and document analysis. Findings showed that the physical educators increased their awareness of responsibility-based teaching strategies, perceived them to positively impact students and integrated the strategies into their teaching. Furthermore, descriptive statistics illustrate frequent use of the teaching strategies and confirms the reliability of the observation instrument. The findings suggest that systematic observations can support responsibility-based CPD for the purposes of research, peer evaluations, or as a reflection tool. The long-term approach enhanced the potential for sustainability.
\end{abstract}

Keywords: Peer observations | Systematic observation | Tools for assessing responsibility-based education

\section{Article:}

\section{Introduction}

Since 2004, the National Standards for Physical Education in the USA have included teaching personal and social responsibility (TPSR) as a content standard (National Association for Sport $\&$ Physical Education [NASPE], 2004). While all physical activities have the potential to promote responsible behavior, such development does not occur automatically. Furthermore, 
different conceptualizations of responsibility might lead to different teaching strategies and student outcomes. Responsibility has been defined broadly as 'adherence to social rules and role expectations' (Wentzel, 1991, p. 2). However, physical educators have explained that 'responsibility requires students to learn how to become accountable for their own well-being and for contributing to the well-being of others, both in and outside the gymnasium' (Parker \& Hellison, 2001, p. 25).

\section{TPSR in physical education}

Hellison's (2011) TPSR model is grounded in the notion that teachers can promote personal and social responsibility through sport and physical activity. It emphasizes student's progression through five levels of personal and social responsibility, including self-control, participation, self-direction, caring and transfer of responsibility to other settings. Four themes characterize the values of TPSR, including a strong teacher student relationship, empowering students, integrating responsibility into physical activity and promoting transfer of responsibility. Although TPSR does provide a lesson format, it provides flexibility for teachers to make adaptations to fit their context. The TPSR model is among the featured main theme curriculum models cited in physical education texts (Lund \& Tannehill, 2010; Metzler, 2005), and has become a component of some physical education teacher education (PETE) programs in the USA (Doolittle, 2011).

The application of TPSR has most often taken place in after-school or community-based programs characterized by voluntary participation and a small number of participants (Hellison, 2011). This contrasts with the compulsory nature of physical education classes that may include students with varying degrees of interest and motivation (Wright, Li, Ding, \& Pickering, 2010).

Research on TPSR in physical education has increased over the last decade (Hellison \& Martinek, 2006). This research has shown some promise for implementing TPSR in school settings. For example, Wright and Burton (2008) examined the implementation of TPSR in a high school class. The study demonstrated that the model can foster a positive learning environment and impact student behavior. However, it also revealed some limitations related to students' disengagement in a compulsory physical education program. Researchers in Valencia, Spain reported successfully implementing the TPSR model following an intensive teacher training process. The students and teachers reported improvements in students' self-control in conflict resolution and respect for others. Furthermore, quantitative findings demonstrated improvements in students' self-efficacy for enlisting social resources. The teachers emphasized that implementing TPSR requires a high level of commitment and works best when integrated into the whole educational community (Escarti, Gutierrez, Pascual, \& Llopis, 2010; Escarti, Gutierrez, Pascual, \& Marin, 2010). The ultimate goal of TPSR, transferring positive behavior outside of the program, has not been demonstrated in physical education (Gordon, 2010).

\section{Continuing professional development}


A large body of educational research provides guidelines for planning and implementing effective continuing professional development (CPD) programs (Darling-Hammond \& Richardson, 2009). Research-supported CPD programs are ideally long-term, include follow-up, encourage collegiality and collaboration, foster a shared vision among teachers, acknowledge teachers' existing beliefs and practices and make use of an outside facilitator (Richardson, 2003). While these elements are preferred, a traditional one- or two-day workshop model of CPD persists (Armour \& Yelling, 2007; Bechtel \& O'Sullivan, 2007; Webster-Wright, 2009). Baird (1992) asserts that research-based CPD programs are hindered by school contexts that fail to encourage teachers' systematic inquiry into their work along with university research agendas that are typically separate from practice.

Much of the knowledge base for professional development in physical education is based on the broader literature in education (Ward \& Doutis, 1999). Educational researchers have identified several key tenets to effective professional development programs including: (1) they are long term, (2) teachers are active participants and (3) activities should be coherent with the teacher's goals (Birman, Desimone, Porter, \& Garet, 2000). Despite this consensus, professional development research seems to have had little documented impacts on education practices as traditional CPD programs persist (Webster-Wright, 2009). Borko (2004) asserts that many CPD programs suffer because overly simplistic and not embedded in teacher's working contexts. Traditional CPD formats are described as being brief and sporadic, such as a one-day workshop that lacks follow-up. Alternative models include a significant amount of contact hours over time, which seems to be more impactful on practice (Guskey, 2002).

In physical education, several similar features have been identified as key tenets of effective in-service education including: (1) recognition of teachers as adult learners, (2) teacher ownership, (3) collegiality, (4) practicality, (5) administrative support and (6) providing an adequate amount of time for change (Doolittle \& Schwager, 1989; Ward, Doutis, \& Evans, 1999). Armour and Yelling (2007) emphasize the importance of informal collaboration among teachers in professional development programs and suggest that professional development can be embedded in practice. Physical educators have also advocated for universities to partner with schools to link research to practice (Hellison et al., 2000; Patton, in press; Siedentop \& Locke, 1997).

Responsibility-based professional development

Martinek and Hellison (2009) note that more research is needed on program leaders (e.g. teachers) related to their learning and implementation of the TPSR model. Doolittle (2011) outlined nine different strategies that have been employed in PETE including: (1) apprenticeships, (2) site-based practicums, (3) workshops and shortcourses, (4) one-week intensive electives, (5) semester long electives, (6) within required activity courses, (7) within methods courses, (8) after-school program based and (9) as a framework for a teacher education program. Many of the successful PETE programs were led by well-established TPSR scholars 
and practitioners. Those programs that were long-term and included expert feedback seemed to be most effective (Doolittle, 2011).

University researchers have often been facilitators of in-service professional development. For example, Gordon's (2010) mixed method study utilized a quasi-experimental design to examine one teacher's implementation of TPSR over a six month period. Data were collected through interviews, observations and student self-assessments. The findings suggest that the students became more responsible and developed a greater understanding of personal and social responsibility. Furthermore, the findings provide support for the notion that the TPSR model can be relevant for in-service physical educators. Similarly, a long-term self supervision process was an effective method for implementing TPSR in a Canadian elementary school (Beaudoin, Brunelle, \& Spallanzani, 2010). These studies support Buchanan's (2001) assertion that frequent reflection may facilitate higher fidelity.

Researchers in Valencia, Spain used a 20-hour training course to introduce two teachers to the theoretical and methodological basis of TPSR. The study provides contrasting examples of implementation fidelity. The authors summarized that the high implementation was facilitated by positive student outcomes. In contrast, weak implementation was associated with fewer positive student outcomes. Furthermore, the teacher's personal style and philosophy served as a facilitator to implementation in the successful case and a hindrance in the other. The authors' called for future studies to address fidelity of implementation in a systematic way (Pascual et al., 2011).

The TARE Observation Instrument was designed to align with the TPSR model. To develop the content of the TARE, the authors drew upon over a decade of experience as a TPSR practitioner and researcher, literature related to TPSR, other well-established systematics observation instruments and consultations with a panel of experts. The instrument has been field tested in secondary physical education settings and was shown to meet rigorous standards for inter-rater reliability (Wright \& Craig, 2011).

\section{Systematic observation in physical education}

Systematic observation tools provide a reliable strategy to collect specific information about activities and events in a classroom (Behets, 1993). They are a common feature of PETE, and may also be a valuable tool for the CPD of in-service teachers (De Marco, Mancini, Wuest, \& Schempp, 1996). It has been argued that 'decisions made in the interest of improving instruction that are based on self-confrontation and an understanding of systematic [observations] are virtually certain to produce targeted gains' (Kindsvatter, Wilen, \& Ishler, 1988, p. 329). However, few examples are available in the physical education literature to demonstrate how systematic observation tools can be employed as an in-service professional development tool. Systematic analyses in physical education date back to the 1970s (Anderson, 1980; Lawson, 1990). Their purpose has been to observe, record and analyze teachers' and students' actions with some assurance that different observers would reach similar conclusions (Darst, Zakrajsek, \& Mancini, 1989). Dougherty (1971) emphasized the important role of systematic 
observations for increasing teachers' awareness of their interactions with students. Systematic observations have facilitated increased awareness among pre-service teachers and helped to increase the amount of effective instructional strategies employed (Mancini, Wuest, \& van der Mars, 1985). Furthermore, pre-service teachers' preferred systematic feedback over conventional feedback from a university supervisor (Siedentop, 1981). Hence, systematic feedback has been shown to support professional development. Since initially being introduced in 2009, the TARE instruments have been field tested in the USA and Spain. Scholars and practitioners suggest that this form of systematic observation can assist in responsibility-based CPD (Coulson, Irwin, \& Wright, 2012; Wright, 2012).

The purpose of this study was to provide a novel responsibility-based CPD experience to three physical educators and examine its impact on a middle school physical education program. The study design was inspired by the growing literature base that calls for CPD research related to responsibility-based teaching (Martinek \& Hellison, 2009) and for CPD programs to be long-term, continual, connected to the classroom and include informal collaborative learning (Armour, Makopoulou, \& Chambers, 2009; Darling-Hammond \& Richardson, 2009; Fullan, 1992; Guskey, 2002).

\section{Methods}

Overview

This project was part of a larger physical education reform initiative. A university institutional review board approved the research and consent was obtained from all participants and the local school district. Three participants were chosen through purposeful sampling, based on their interest integrating responsibility-based teaching strategies. Each participant was enlisted as key contributors to this study by asking them to undergo training and to engage in systematic observations of responsibility-based teaching. The intention of the training was to empower the teachers to systematically observe their peers and conduct self-reflections. The TARE Observation Instrument and Post-teaching Reflection were used to facilitate this process (Hellison, 2011; Wright \& Craig, 2011).

Setting

This study took place at Southside Middle School, a public coeducational school located in mid-sized city in the American Midwest that includes all of the fifth- and sixth-grade (aged 1012) students in the Langston School Corporation. Among the 1000 students, over half of the students were white (59\%), 13\% were black, 20\% were Hispanic and 7\% were multiracial. Seventy-three percent of students were on the free or reduced lunch program, a common metric used to identify students whose families live at or below the poverty level. The 'Warrior Way' is the school theme that encourages students to 'be safe, be respectful, be responsible, be positive.' 
The school was in the final year of a three-year federal grant that funded substantial upgrades to facilities, new equipment and curricular reform through CPD. Faculty and graduate students from a local university, including the authors, worked closely with the school to provide CPD experiences and conduct research. Throughout the day, there are seven physical education periods that range from 45 to 50 minutes in length. Class sizes varied, the smallest class had 17 students and the largest class had 39 students.

Participants

Three in-service physical educators participated in this study. Sally served as chair of the physical education department and has taught at Southside for 23 years. Dolly splits time between teaching physical education and health. She has over 30 years of experience. John was in his first year at Southside. However, he has over 20 years of teaching experience. Prior to teaching at Southside, he taught history for 15 years.

\section{CPD protocol and data collection}

\section{CPD research tools}

The TARE Observation Instrument is comprised of three parts. Part One uses time-sampling methodology in five-minute intervals to document teachers' use of nine discrete teaching strategies (modeling respect, setting expectations, opportunities for success, promoting social interaction, assigning tasks, leadership, giving voices and choices, assessment and transfer). Part Two of the instrument provides a holistic assessment of TPSR themes (integration, transfer, empowerment and teacher student relationship) with scores ranging from never (0) to extensively (4). Part Three provides a holistic assessment of student responsibility in the categories of self-control, participation, effort, self-direction and caring with scores ranging from very weak (0) to very strong (4). Space for contextual comments is provided in each section of the instrument.

The TARE Post-teaching Reflection is a self-report compliment to the observation instrument. Teachers use this form to assess their own implementation of the responsibility-based teaching strategies on a scale ranging from never (0) to frequently (4). The same holistic assessments and contextual comments are a part of the Post-teaching Reflection.

Training meetings

Each teacher met individually with the lead researcher in two separate training meetings. In the first meeting, the researcher explained the protocol for using timesampling observations. Once the teacher confirmed that they understood the TARE instruments, a practice coding session 
began using video observation. The same videotape was used for each training session. The tape was paused at the end of each five-minute interval to address any questions.

During the second training meeting, the teacher and researcher independently coded a 45-minute videotaped lesson using the TARE Observation Instrument. Following the coding session, the teacher and researcher shared their observations. The purpose of this meeting was to confirm that the teacher had a basic understanding of the responsibility-based teaching strategies and she/he could observe them in practice.

Team observations

The central component of the professional development protocol centers on live observations using the TARE instruments. All three physical education teachers were observed teaching at least two physical education lessons. The observations included three key roles: (1) instructor, (2) peer observer and (3) researcher (see Figure 1). The instructor was a physical education teacher who led all instruction during the observation period. Another physical education teacher served as a peer observer and observed an entire lesson alongside the researcher. The peer observer and researcher utilized the TARE Observation Instrument. Immediately after teaching a lesson, the instructor completed the TARE Post-teaching Reflection. The researcher compiled a summary report after each team observation to facilitate further discussion, reflection and adaptations to future lesson plans.

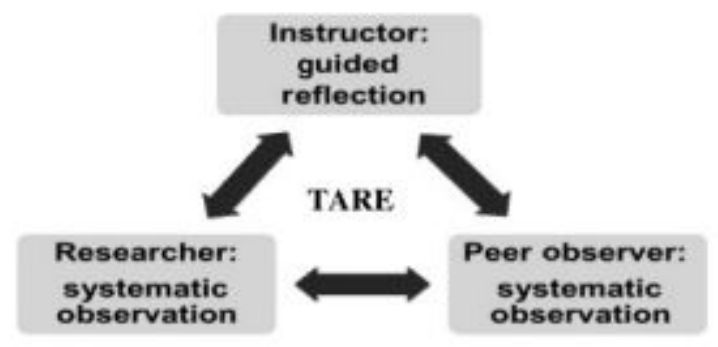

Figure 1. Team observation cycle Note: The team observation cycle was conducted seven times throughout the duration of the study and was facilitated by the tools for assessing responsibility-based education (TARE).

Interviews

Each teacher participated in one individual interview at the end of the CPD protocol. The interview was semi-structured, lasted approximately one hour, and focused on the teachers' experience with the CPD protocol. All interviews were audiotaped and transcribed verbatim for analysis. Sample questions include 'How do you think the CPD prepared you for this 
experience?,' 'How have your students responded to responsibility-based teaching strategies?,' and 'What changes could be made to make this experience better?'

Nonparticipant observations

The lead researcher visited Southside Middle School two times per week over a fourmonth period. During the visits, the lead researcher observed physical education classes and had informal discussions with the teachers about their ongoing effort to implement responsibility-based teaching strategies. Following each visit, the lead researcher audio-recorded field notes and transcribed them for analysis.

Video observations

Separate from the team observations, 10 physical education lessons were videotaped for systematic analysis using the TARE Observation Instrument. Prior to the video observations, the researcher and another graduate student were trained to conduct systematic analyses using the TARE Observation Instrument.

\section{Data analysis}

Quantitative analysis

The investigator and a graduate student were trained to use the TARE Observation Instrument by the author of the instrument. Following the procedures outlined by Wright and Craig (2011), reliability scores were calculated across all team observations and videotaped observations. The minimum standard of 0.80 was used for reporting percent agreement of systematic observations. There was no minimum standard for reporting percent agreement of the team observations. Sections 2 and 3 of the instrument rely on Likert scales and inter-reliability focuses on whether or not the raters were consistent rather than the exact amount to which they agree or disagree (Uebersax, 1992). In this case, the percentage of agreement within one point on the Likert scale is reported. A summary of all team observations and systematic observations is provided in a comprehensive manner.

Qualitative analysis

This study employs typological data analysis (Hatch, 2002). A typological analysis begins by dividing the overall data set into categories based on predetermined typologies, which can be based on theory, common sense or research objectives. The predetermined typologies included the individual teachers, the school, the TARE instruments and CPD. Once the typologies were organized into categories, an inductive analysis was conducted and themes were developed 
within each category. Following this, the themes were compared with those from the other categories. The resulting themes were supported by multiple data sources and evident within each of the typologies. A qualitative software program was used to facilitate data management (QSR International, 2010).

\section{Trustworthiness}

Multiple data sources were used to promote triangulation. Peer debriefings were implemented to allow the teachers to confirm or deny the researchers' findings. Furthermore, this study enlisted the teachers in the research process and allowed for researcher triangulation of systematic observations. Finally, the lead researcher was engaged in the research setting for two years prior to the beginning of this study (Patton, 2002).

\section{Results}

Videotaped observations

Systematic observations (10 lessons, 84 intervals) yielded high levels of reliabilities across all nine categories. As illustrated in Table 1, percent agreement across 84 videotaped intervals ranged from 88.1 to $100 \%$. Holistic measures of personal and social responsibility themes (see Table 2) and student responsibility levels (see Table 3) also exceeded recommended levels for interobserver reliability (Uebersax, 1992; Wright \& Craig, 2011).

Table 1. Reliability of observable teaching strategies from systematic observations

\begin{tabular}{|l|l|l|l|l|l|l|l|l|l|}
\hline & $(\mathrm{M})$ & $(\mathrm{E})$ & $(\mathrm{S})$ & $(\mathrm{SI})$ & $(\mathrm{T})$ & $(\mathrm{L})$ & $(\mathrm{V})$ & $(\mathrm{A})$ & $(\mathrm{Tr})$ \\
\hline $\begin{array}{l}\text { Personal } \\
\text { agreement }\end{array}$ & 100 & 96.43 & 97.62 & 95.24 & 88.10 & 94.05 & 92.86 & $91.7^{\circ}$ & 96.43 \\
\hline
\end{tabular}

Key: (M)odeling respect; setting (E)xpectations; opportunities for (S)uccess; fostering Social (SI)nteraction; assigning (T)asks; (L)eadership; giving choices and (V)oices; role in (A)ssessment; (Tr)ansfer.

Table 2. Percentage agreement for TPSR themes from systematic observations

\begin{tabular}{|l|l|l|l|}
\hline & Exact (\%) & Within 1 (\%) & Within 2 (\%) \\
\hline Integration & 50 & 100 & n/a \\
\hline Transfer & 100 & $\mathrm{n} / \mathrm{a}$ & $\mathrm{n} / \mathrm{a}$ \\
\hline
\end{tabular}




\begin{tabular}{|l|l|l|l|}
\hline Empowerment & 30 & 90 & 100 \\
\hline Teacher-student relationship & 90 & 100 & $\mathrm{n} / \mathrm{a}$ \\
\hline
\end{tabular}

$\mathrm{n} / \mathrm{a}=$ not applicable.

Team observations

Reliability scores from the team observations (seven lessons, 63 intervals) done by the physical education instructors and the researcher had lower reliability scores than the systematic observations. However, each category exceeds $70 \%$ agreement (see Table 4). Teaching strategies that tend to be discrete had lower reliability scores and those that are usually continuous received higher scores. Tables 5 and 6 illustrate that the team observations met the acceptable standards for observer reliability.

Implementation fidelity

To assess implementation fidelity of the professional development protocol, the results from the team observations (n7) are compared with the results from the systematic observations (n10). Figure 2 illustrates the frequency of the nine responsibility-based teaching strategies. The data suggest that the three teachers modeled respectful communication and behavior with their students $100 \%$ of the time. The teaching strategies setting expectations, providing opportunities for success, promoting social interaction and assigning task were used extensively. Leadership, giving voices and choices and assessment were used less frequently but were clearly a part of the physical education lessons. Transfer was rarely addressed according to all of the reports.

Figure 3 shows close agreement on three of the four categories for TPSR themes. However, transfer was rated consistently higher by the peer teacher than the researcher. Disagreements such as this served as learning experiences for both the teachers and the researcher. Upon inquiring about the discrepancy in the transfer categories, the teachers replied that they valued "skill transfer'" as much as the transfer of life skills. For example, emphasizing that practicing volleyball skills could lead to improved basketball skills was a transfer strategy that was used to encourage some boys who were not enthusiastic about volleyball. The students' level of responsibility ranged from moderate to strong (see Figure 4).

Table 3. Percentage agreement for student responsibility from systematic observations

\begin{tabular}{|l|l|l|l|}
\hline & Exact (\%) & Within 1 (\%) & Within 2 (\%) \\
\hline Self-control & 90 & 100 & n/a \\
\hline Participation & 100 & n/a & n/a \\
\hline
\end{tabular}




\begin{tabular}{|l|l|l|l|}
\hline Effort & 40 & 100 & $\mathrm{n} / \mathrm{a}$ \\
\hline Self-direction & 60 & 100 & $\mathrm{n} / \mathrm{a}$ \\
\hline Caring & 80 & 100 & $\mathrm{n} / \mathrm{a}$ \\
\hline
\end{tabular}

Table 4. Reliability of observable teaching strategies from team observations

\begin{tabular}{|l|l|l|l|l|l|l|l|l|l|}
\hline & $(\mathrm{M})$ & $(\mathrm{E})$ & $(\mathrm{S})$ & $(\mathrm{SI})$ & $(\mathrm{T})$ & $(\mathrm{L})$ & $(\mathrm{V})$ & $(\mathrm{A})$ & $(\mathrm{Tr})$ \\
\hline Percent agreement & 100 & 77.78 & 85.71 & 80.95 & 71.43 & 92.06 & 71.43 & 84.13 & 87.30 \\
\hline
\end{tabular}

Key: (M)odeling respect; setting (E)xpectations; opportunities for (S)uccess; fostering social (SI)nteraction; assigning (T)asks; (L)eadership; giving choices and (V)oices; role in (A)ssessment; (Tr)ansfer

Thematic results

Overall, the teachers viewed the CPD protocol positively. Dolly commented that the CPD protocol 'helped me become much more aware and much more focused,' and Sally noted that 'It's very helpful to go back and review some of these things.' John indicated that 'I really liked the [TARE] tool because it gives you something to actually write down ...I like to write things down as to why I saw it and what I was thinking about when I saw something.' The teachers often made comments like 'I enjoyed it' and 'this is a really good program.' Qualitative analysis revealed the following themes: (1) increased awareness, (2) positive impact on students and (3) integrated instructional approaches.

Increased awareness

The three teachers reported that the TARE training and team observations increased their awareness of the nine responsibility-based teaching strategies and made them more likely to use them. For example, Dolly linked her awareness to the TARE instruments:

I think that sitting there and circling and making yourself aware of the criteria, I think that really helps. It helped me become much more focused. I am a visual learner...So I really think it's fairly good that we are watching other people because it helps focus in and think "Do I do that? 
Table 5. Percent agreement for TPSR themes from team observations

\begin{tabular}{|l|l|l|l|}
\hline & Agree (\%) & Within 1 & Within 2 \\
\hline Integration & 57.14 & 85.71 & 100 \\
\hline Transfer & 42.86 & 85.17 & 100 \\
\hline Empowerment & 57.14 & 85.17 & 100 \\
\hline T-S Relationship & 85.17 & 100 & $\mathrm{n} / \mathrm{a}$ \\
\hline
\end{tabular}

Table 6. Percentage agreement for student responsibility from team observations

\begin{tabular}{|l|l|l|l|}
\hline & Agree (\%) & Within 1 (\%) & Within 2 (\%) \\
\hline Self-control & 28.57 & 85.71 & 100 \\
\hline Participation & 57.14 & 100 & $\mathrm{n} / \mathrm{a}$ \\
\hline Effort & 57.14 & 100 & $\mathrm{n} / \mathrm{a}$ \\
\hline Self-direction & 42.86 & 85.71 & 100 \\
\hline Caring & 42.86 & 100 & $\mathrm{n} / \mathrm{a}$ \\
\hline
\end{tabular}

When asked how the CPD experience impacted his teaching, John replied that:

It has changed a little bit maybe but not how I basically go about [teaching]. But it has made me more aware that it is important that I hit these things, let them have a voice in it, let them have a choice in it, let them kind of set the parameters...it probably helped me be more aware and helped me stop trying to tell them everything and just let them know what we expect.

Sally echoed this sentiment in her remarks about conducting peer observations:

Seeing all the different teaching strategies reminds me that "oh yea I do do that, but maybe I don't do that." Just seeing it on paper and evaluating or being evaluated makes you start to think about "am I really modeling respect, am I setting the expectations, am I letting kids be leaders?

The teachers often used the comments section of the TARE instrument to make notes about their peer teacher. While observing Dolly, John noted that she 'could have used the kids to demo on the jungle gym.' Here, he recognized an opportunity to assign tasks during the lesson. However, 
he also noted that Dolly 'did a nice job of explaining exactly what she was looking for and what the students were to do.' Each team observation included contextual notes that pointed out the peer teacher's strengths and sometimes areas for improvement.

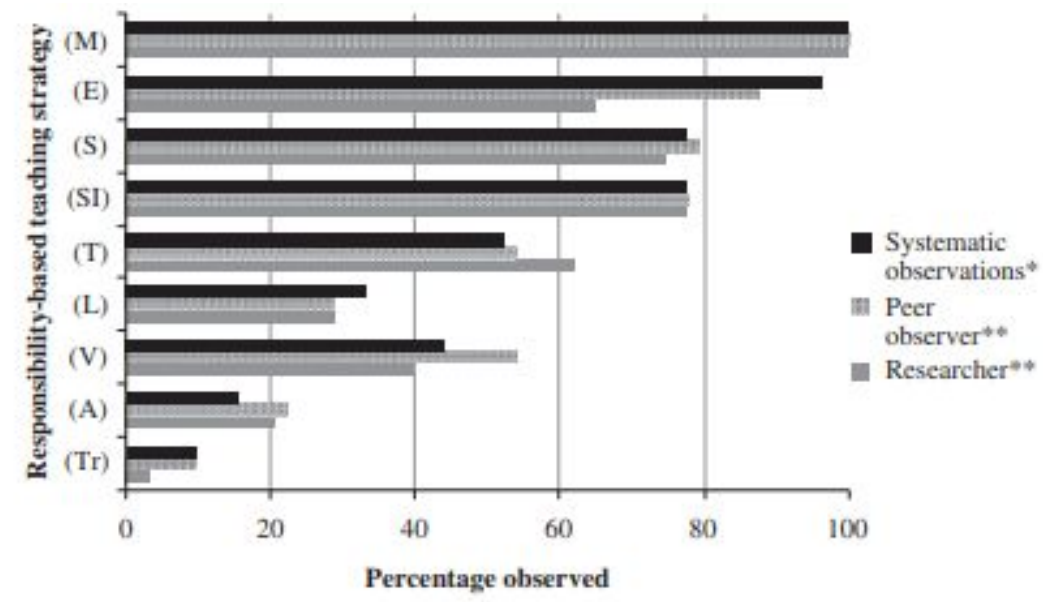

$\mathbf{M}=$ Modeling Respect; $\mathbf{E}=$ Setting Expectations; $\mathbf{S}=$ Opportunities for Success;

SI $=$ Fostering Social Interaction; $\mathbf{T}=$ Assigning Tasks; $\mathbf{L}=$ Leadership

$\mathbf{V}=$ Giving Voices and Choices; $\mathbf{A}=$ Assessment; $\mathbf{T r}=$ Transfer

*10 lessons observed, 84 intervals

$* * 7$ lessons observed, 63 intervals

Figure 2. Observable teaching strategies

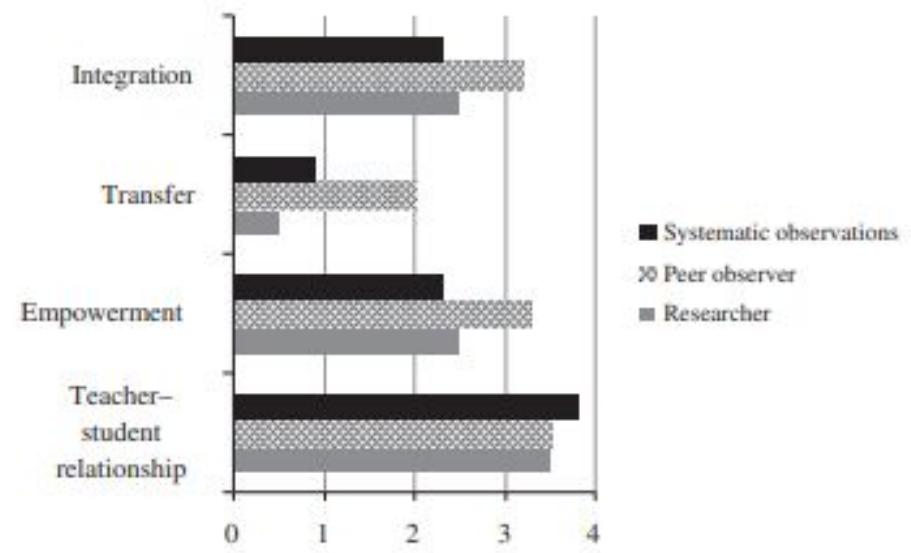

$0=$ Never observed; $1=$ Rarely; $3=$ Frequently; and $4=$ Extensively

10 lessons were observed during systematic observations and 7 lessons were observed during team observations (including peer observer and researcher).

Figure 3. Personal-social responsibility themes 


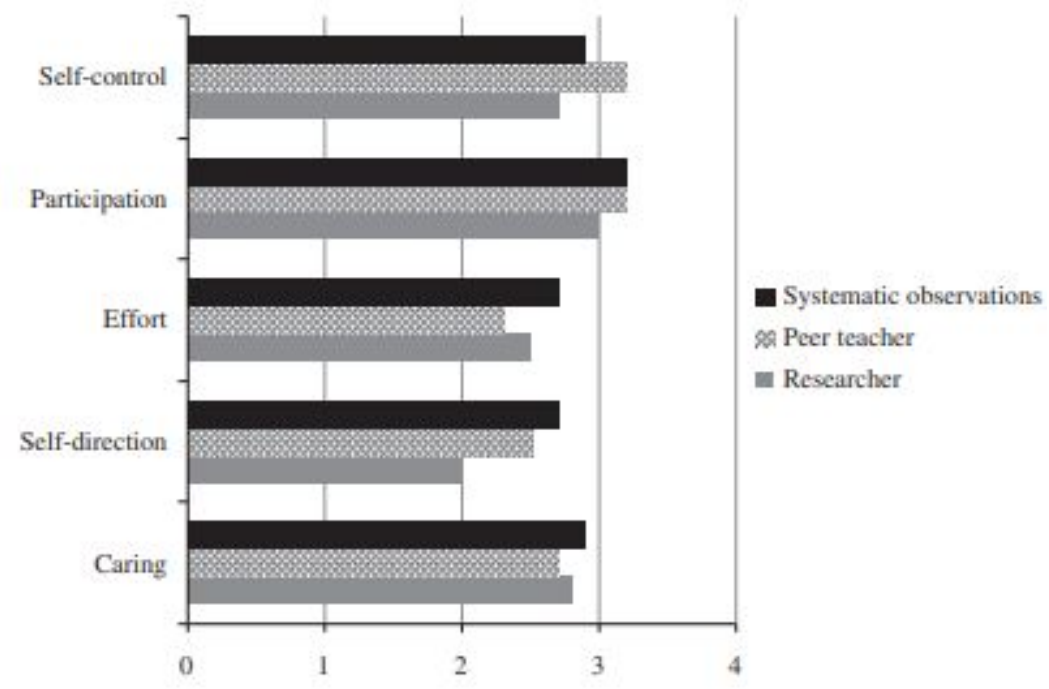

10 lessons were observed during systematic observations and 7 lessons were observed during team observations (including peer observer and researcher).

Note: The names of levels vary in different iterations of the TPSR literature. This chart reflects the levels as they are described on the Tools for Assessing

Responsibility-based Education (Wright \& Craig, 2011).

Figure 4. Student levels of responsibility

The TARE Post-teaching Reflection also provided multiple examples of how the teachers' became more aware. Following a 'tough day,' Sally noted that 'I didn't feel like I had a lot of positive energy to share with my class...by the end of the day I was very frustrated with my students.' More specifically, her notes indicated that there were 'not a lot of tasks today' and 'I don't believe I addressed transfer this hour.' On a more positive day, Sally reported that 'coaches debriefed at the end of class,' and 'everyone will answer questions about how things are going and give a self assessment.' In these examples, Sally recognized several opportunities to implement responsibility-based teaching strategies and she assessed her teaching. Dolly noted that 'I know I have poor tone at times' and 'I set clear expectations.' Although the teachers became more aware of transfer, John notes that '[transfer] remains the toughest to do. I've noticed that unless I intentionally plan it, it usually does not get done but it is so important.'

Positive impact on students

The teachers perceived the responsibility-based teaching strategies to have a positive impact on their students. During observations, the researcher periodically asked how the students were doing with the responsibility-based teaching strategies. The remarks were almost always positive. Following a visit to the school, the lead researcher's notes reported that:

The physical education classes are still in their volleyball units and each team has coaches...they are at a point where they kind of know what is going on. It is a lot 
smoother. Sally commented that it is a little less stressful now because the coaches understand their roles and what they are supposed to do.

John wrote in his reflection that the 'coaches know the jobs and they usually let other students/teammates know what they are supposed to do.' He went on to write that 'we work on [self-control] every day now and it has been improving.' When asked what, specifically, the students were learning, Dolly replied that:

Some kids are really being more empathetic toward kids with special needs or kids that were different from them. They were learning, and I don't know if its leadership but I guess it is because they are learning empathy, they are learning to communicate, they are learning to be helpers and they are learning to lead by example.

Consequently, the teachers say that responsibility-based teaching will be the 'center focus' and a 'building block' of the Southside physical education program.

Integrated instructional approaches

Data analysis revealed that the three teachers integrated the responsibility-based teaching strategies with their school's pre-existing strategies. Furthermore, they made adaptations to the TARE categories to suit their teaching context. John pointed out that the responsibility-based teaching strategies 'fit right in with the [Warrior Way], particularly with the respect and responsibility.' Dolly echoed that comment, 'I think that our school, the Warrior Way, we are trying to focus on this type of a model and it fits perfectly with what we are doing.' More specifically, Dolly talked about the connection between the Warrior Way and life skills:

I end my class every day, every single class period with ' be respectful, be responsible, be positive,' you know that's the Warrior Way. So kids are hearing that, but so what? Is that safe, is it respectful, is it positive? I have tried, when I am talking about discipline with a kid when they are in trouble, I ask them, "Is that safe?" [Student]: "No." "Is that responsible?" [Student]: "No.' "'Is that respectful?"' [Student]: "No." "'How can we turn this into a positive?" ...I say, "Now what is this all about?" [Student]: "The Warrior Way!" But they are hearing those words, they are seeing those words, they need to figure out how and why we are putting this into practice and to me it's a life skill.

For these teachers, emphasizing responsibility-based teaching strategies in physical education gave them an opportunity to show students how the Warrior Way can be applied to everyday life.

After learning about the nine responsibility-based teaching strategies, the teachers made some adaptations to suit their own context. For example, the teachers' expanded the definition of transfer to include 'skill transfer,' as John noted: 
I do think it is important to make that connection not only with the social responsibility but with the skills connection as well since one of our goals in physical education is to make students aware of the need to be life-long learners.

Field notes from observations documented several instances where the teachers used the concept of skill transfer. Their conceptualization of skill transfer suggests that giving effort in physical education class can help develop skills that can transfer to other physical activities. This was often used to motivate students to participate in activities they did not like.

In addition to the nine responsibility-based teaching strategies, the teachers indicated that positive reinforcement is one of their primary responsibility-based teaching strategies, as Dolly explained:

You know, we do a lot of positive talk. I don't know if that's really a part of the TARE. But we do a lot of positive talk and I don't know where to put that. Because to me, if I am going to say something negative to a kid, I need to make sure I say three or four things positive to that kid too.

The teachers' use of the skill transfer concept and positive reinforcement demonstrates their integration of responsibility-based teaching strategies with their own teaching strategies.

John took the initiative to address transfer by introducing the TARE instruments to a classroom teacher. He reported on his contextual notes of a TARE report that he was 'anxious to see how it [TARE] works in a social studies class.' The following week, John observed the social studies teacher for two class periods. He took extensive notes documenting the teacher's use of responsibility-based teaching strategies and making connections between some strategies that the social studies teacher used more successfully than the physical education teachers. That prompted the researcher to ask John why this seemed so important to him. He replied that:

Sometimes you think "what are we preparing kids to do?" This is a great tool to be able to assess that. We are saying over and over again that when you get into the real world and get a job, you are going to have to work together with people; you are going to have to show respect to people, you are going to have to communicate well. I thought it was a great tool. I felt like it would help a social studies teacher or whatever you're teaching. To let kids know, you are not just learning this for the sake of learning it. Even though you might not use the material you are using the process of how you are learning it in your real life.

\section{Discussion}

The findings from this study support the notion that systematic observations can be a facilitator of professional development for in-service physical education teachers. The three 
teachers frequently employed responsibility-based teaching strategies, the TARE instruments provided an accessible strategy for peer assessments, and there is evidence that the strategies were implemented with high fidelity. Following the initial publication of the TARE Observation Instrument in 2011, this study provides further support for its reliability and applicability to physical education. Hence, researchers may also employ the TARE instruments to assess the National Standard for Physical Education related to TPSR (Parker \& Hellison, 2001; Wright \& Craig, 2011).

Reliability scores for the team observations all exceeded $70 \%$, which is often an acceptable level for reporting (Riffe, Lacy, \& Fico, 1998). While these scores were lower than the systematic observations, this was expected based on several factors. First, the team observations do not afford opportunities to pause in between intervals or review a segment for clarity. Second, the teachers' training was relatively brief and less rigorous the researcher's training. Third, the teachers seemed more likely to base their perceptions of responsibility-based teaching strategies on their practical experience, whereas the researcher was more likely to adhere to the operational definitions. Finally, disagreements were viewed as an opportunity for discussion and reflection.

The teachers' willingness to accommodate the semester-long CPD protocol is reflective of their high level of commitment to responsibility-based teaching. This study supports the literature that suggests that in order to teach responsibility:

Physical educators must first believe that they will be better teachers if they listen to their students, that their students have the capacity to make decisions that matter, and that these students will be more responsible as a result of this approach. (Parker \& Hellison, 2001, p. 27)

The teachers in this study clearly held such beliefs as indicated by their daily activities.

Collaboration among teachers is a key contributor to instructional improvement (Darling-Hammond, 2010; Warren Little, 2002). The collaboration described in this study was enhanced by systematic observations and continuous interaction with a researcher knowledgeable in TPSR. The collaboration was active, goal oriented, reflective, somewhat self-regulated and social, all of which are key to constructivist learning (Simons, 1993). This study demonstrates one example of a CPD protocol that aligns with research that calls for CPD programs to be reconceptualized in a way that places teachers at the center, is long term, and includes peer- and selfassessments in addition to expert feedback (Armour \& Yelling, 2007). The TARE instruments were the central component that helped sustain a focus on responsibility-based teaching throughout the four-month process.

Evidence showed that the physical educators often reflected on their own teaching as a consequence of observing their peers. Such reflection can stimulate self-inquiry and support professional grown (Collier, 2009). By the end of the semester, the teachers were envisioning a physical education curriculum that is grounded in responsibility-based teaching. The ongoing 
nature of the CPD protocol appears to have allowed sufficient time for the teachers to engage in an experiential learning process that produced a deeper understanding of responsibility-based teaching in physical education (Rovegno, 2003).

This study has several limitations. The three participants in the study were chosen because of their preference to focus more on TPSR and their extensive collaboration is evident in the cooperative nature of the CPD protocol. Such circumstances may not be available in other physical education settings. Those factors enhanced the efficacy of this study but could hinder a similar study in a different setting. There was also a shift in time while periodically measuring teacher's implementation of responsibility-based teaching strategies. This study was unable to account change over time or how students' behavior may influence the use of responsibility-based teaching strategies.

\section{Conclusion and implications}

Overall, the responsibility-based CPD protocol provided a positive experience to the three middle school teachers. Several conclusions can be drawn. First, the observations were scheduled periodically at times convenient to the teachers, which seemed to support a long-term CPD protocol embedded in teachers' practice (Birman et al., 2000; Doolittle \& Schwager, 1989; Richardson, 2003). The three teachers were able to implement the strategies at their own pace and then began to see the fruits of their labor through its impact on students (Guskey, 2002). Second, peer- and self-assessments were facilitators of formal and informal reflections and collaboration (Armour \& Yelling, 2007). Third, team observations that were facilitated by the TARE instruments demonstrated a level of fidelity and confirmed that responsibility-based teaching strategies were commonly employed (Wright \& Craig, 2011). Finally, the professional development protocol facilitated teachers' systematic inquiry into their work while also meeting the needs for data collection (Baird, 1992). Hence, this approach served as a mutually beneficial partnership between the university researchers and the school (Doolittle \& Schwager, 1989; Hellison et al., 2000; Hemphill, Richards, Blankenship, Beck, \& Keith, 2012).

Upon introducing the TARE instruments in 2009, Wright and Craig (2009) suggested that the tools were created for assessment purposes but could also assist in training programs. However, no specific guidelines were provided to indicate how the TARE instruments can be utilized as training tools. This study confirms their utility for collecting empirical data research on teachers' use of responsibility-based teaching strategies and provides a model for using the TARE instruments as teacher training tools. Importantly, the teachers' training and experience using the instruments empowers them to continue to assess their teaching and promotes sustainability of the CPD protocol.

This study also has implications for future research. It provides one example of a novel responsibility-based CPD protocol. In Borko's (2004) three-phase model, this type of research would be classified as the first phase of CPD research. Future research could move toward more advanced stages of CPD research. The second phase examines ways in which the CPD protocol 
can be enacted with fidelity in different settings, with different participants and different CPD providers. The third phase builds on the previous by enacting the CPD on a large scale to provide comparative data about the implementation, impacts and resources needed for a responsibility-based CPD program. Since in-service workshops are the most common form of CPD in physical education (Bechtel \& O'Sullivan, 2007) those workshops could be redesigned to train teachers in the foundations of responsibility-based teaching and then empower them to assess their own programs.

Further research is needed to establish the reliability of team observations conducted by in-service teachers as well as the training to prepare them. Given the interactive nature of physical education classes, it seems likely that live observations in a gymnasium will not be as reliable as videotaped observations conducted in a controlled environment. However, the act of conducting the observation and then sharing that feedback immediately with a peer teacher serves as a form of collaboration that can facilitate improved teaching and collegiality (Armour \& Yelling, 2007).

While this study focused on teacher's instructional practices, the most important consideration of this type of research is the impact on student learning (Opfer \& Pedder, 2011). The teachers and the researcher hoped that the increased use of responsibility-based teaching strategies might lead students to be more personally and socially responsible in physical education settings and beyond. While such outcomes were beyond the scope of this study, future research is needed to link the responsibility-based teaching strategies to student outcomes.

Finally, this study focused mostly on nine responsibility-based teaching strategies as they are defined on the TARE instrument. However, teachers employ a wide range of tactics to promote responsibility in physical activity settings that may not be captured through systematic observation. As research into responsibility-based CPD develops, particularly for in-service teachers, more attention should be paid to contextual factors that facilitate TPSR.

\section{References}

Anderson, W. (1980). Analysis of teaching in physical education. St. Louis: C.V. Mosby. Armour, K., Makopoulou, K., \& Chambers, F. (2009). The learning teacher in physical education. In L. Housner, M. Metzler, P. Schempp \& T. Templin (Eds.), Historic traditions and future directions of research on teaching and teacher education in physical education (pp. 213220). Morgantown, WV: Fitness Information Technology.

Armour, K., \& Yelling, M. (2007). Effective professional development for physical education teachers: The role of informal, collaborative learning. Journal of Teaching in Physical Education, 26, 177200.

Baird, J. (1992). Collaborative reflection, systematic enquiry, better teaching. In T. Russell \& H. Munby (Eds.), Teachers and teaching: From classroom to reflection (pp. 3348). London: The Falmer Press. 
Beaudoin, S., Brunelle, J., \& Spallanzani, C. (2010, October). Implementing TPSR model in physical education: Benefits of a self-supervision process. Paper presented at the International Association for Physical Education in Higher Education - World Congress, A Coruña, Spain.

Bechtel, P., \& O'Sullivan, M. (2007). Enhancers and inhibitors of teacher change among secondary physical educators. Journal of Teaching in Physical Education, 26, 221235.

Behets, D. (1993). Systematic observation for preservice physical education teachers. Physical Educator, 50, 8795.

Birman, B., Desimone, L., Porter, A., \& Garet, M. (2000). Designing professional development that works. Educational Leadership, 57, 2833.

Borko, H. (2004). Professional development and teacher learning: Mapping the terrain. Educational Researcher, 33, 315. doi:10.3102/0013189X033008003

Buchanan, A. (2001). Contextual challenges to teaching responsibility in a sports camp. Journal of Teaching in Physical Education, 20, 155.

Collier, C. (2009). Teacher learning within an inquiry model of PETE. In L. Housner, M. Metzler, P. Schempp \& T. Templin (Eds.), Historic traditions and future directions on teaching and teacher education in physical education (pp. 356363). Morgantown, WV: Fitness Information Technology.

Coulson, C., Irwin, C., \& Wright, P. M. (2012). Applying Hellison's responsibility model in a residential treatment facility, Agora for Physical Education \& Sport, 14(1), 3854. Retrieved from https://www5.uva.es/agora/revista/14_1/agora14_1d_coulson_et_al.pdf

Darling-Hammond, L. (2010). The flat world and education: How America's commitment to equity will determine our future. New York, NY: Teachers College Press.

Darling-Hammond, L., \& Richardson, N. (2009). Teacher learning: Research shows how schools can create more powerful professional development experience. Educational Leadership, $66,4655$.

Darst, P., Zakrajsek, D., \& Mancini, V. (1989). Analyzing physical education and sport instruction. Champaign, IL: Human Kinetics.

De Marco, G., Mancini, V., Wuest, D., \& Schempp, P. (1996). Becoming reacquainted with a once familiar and still valuable tool: Systematic observation methodology revisited. International Journal of Physical Education, 33, 1726.

Doolittle, S. (2011). TPSR in PE teacher education: One teacher's explorations. In D. Hellison (Ed.), Teaching personal and social responsibility through physical activity (pp. 117147). Champaign, IL: Human Kinetics.

Doolittle, S., \& Schwager, S. (1989). Socialization and inservice teacher education. In T. J. Templin \& P. G. Schempp (Eds.), Socialization into teaching: Learning to teach (pp. 105120). Indianapolis: Benchmark Press.

Dougherty, N. (1971). A plan for the analysis of teacher-pupil interaction in physical education classes. Quest, 15, 3950. doi:10.1080/00336297.1971.10519700 
Escarti, A., Gutierrez, M., Pascual, C., \& Llopis, R. (2010). Implementation of the personal and social responsibility model to improve self-efficacy during physical education classes for primary school children. International Journal of Psychology \& Psychological Therapy, 10, 387 402. Retrieved from http://www.ucm.es/info/Psi/docs/journal/v13_n2_2010/art667.pdf

Escarti, A., Gutierrez, M., Pascual, C., \& Marin, D. (2010). Application of Hellison's teaching personal and social responsibility model in physical education to improve self-efficacy for adolescents at risk of dropping-out of school. The Spanish Journal of Psychology, 13, 667 676. Retrieved from http://www.ijpsy.com/volumen10/num3/269/implementation-of-thepersonal-and-social-E N.pdf

Fullan, M. (1992). Successful school improvement: The implementation perspectives and beyond. Buckingham: Open University Press.

Gordon, B. (2010). An examination of the responsibility model in a New Zealand secondary school phyiscal edcuation program. Journal of Teaching in Physical Education, 27, 138154.

Guskey, T. (2002). Professional development and teacher change. Teachers and Teaching, 8 , 381391. doi:10.1080/135406002100000512

Hatch, J. (2002). Doing qualitative research in educational settings. New York, NY: State University of New York Press.

Hellison, D. (2011). Teaching responsibility through physical activity. Champaign, IL: Human Kinetics.

Hellison, D., Cutforth, N., Kallusky, J., Martinek, T., Parker, M., \& Stiehl, J. (2000). Youth development and physical activity: Linking universities and communities. Champaign, IL: Human Kinetics.

Hellison, D., \& Martinek, T. (2006). Social and individual responsibility programs. In D. Kirk, D. Macdonald \& M. O'Sullivan (Eds.), The handbook of physical education (pp. 610626). Thousand Oaks, CA: Sage.

Hemphill, M. A., Richards, K. A., Blankenship, B. T., Beck, S., \& Keith, D. (2012). Making PALS through partnerships: A collaboration to promote physically active Lafayette students. Journal of Physical Education Recreation \& Dance, 83, 2336.

Kindsvatter, R., Wilen, W., \& Ishler, M. (1988). Dynamics of effective teaching. White Plains, NY: Longman.

Lawson, H. (1990). Sport pedagogy research: From information gathering to useful knowledge. Journal of Teaching in Physical Education, 10, 121.

Lund, J., \& Tannehill, D. (2010). Standards based physical education curriculum development. Sudbury, MA: Jones and Bartlett.

Mancini, V., Wuest, D., \& van der Mars, H. (1985). Use of instruction and supervision in systematic observation in undergraduate professional preparation. Journal of Teaching in Physical Education, 5, 2233. 
Martinek, T., \& Hellison, D. (2009). Youth leadership in sport and physical education. New York, NY: Palgrave Macmillan.

Metzler, M. W. (2005). Instructional models for physical education. Scottsdale, AZ: Holcomb Hathaway.

Mrugala, J. (2002). Exploratory study of responsibility model practitioners (Unpublished doctoral dissertation). University of Illinois, Chicago.

National Association for Sport \& Physical Education [NASPE]. (2004). Moving into the future: National standards for physical education. Reston, VA: Author.

Opfer, V. D., \& Pedder, D. (2011). Conceptualizing teacher professional learning. Review of Educational Research, 81, 376407. doi:10.3102/0034654311413609

Parker, M., \& Hellison, D. (2001). Teaching responsibility in physical education: Standards, outcomes and beyond. Journal of Physical Education Recreation \& Dance, 72, 2536.

Pascual, C., Escarti, A., Llopis, R., Gutierrez, M., Marin, D., \& Wright, P. (2011). Implementation fidelity of a programs designed to promote personal and social responsibility through physical education: A comparative case study. Research Quarterly for Exercise \& Sport, 82, 499511. Retrieved from http://www.ncbi.nlm.nih.gov/pubmed/21957709

Patton, K. (2012). The dynamics of promoting sustained school-university partnerships. Journal of Physical Education Recreation \& Dance, 83, 1336.

Patton, M. Q. (2002). Qualitative research and evaluation methods (3rd ed). Thousand Oaks, CA: Sage.

QSR International. (2010). NVivo 9. Doncaster, Victoria: Author.

Richardson, V. (2003). The dilemmas of professional development. Phi Delta Kappan, 84, 401411.

Riffe, D., Lacy, S., \& Fico, F. (1998). Analyzing media messages: Using quantitative content analysis in research. Mahwah, NJ: Erlbaum.

Rovegno, I. (2003). Teachers' knowledge construction. In S. Silverman \& C. Ennis (Eds.), Student learning in physical education (pp. 295310). Champaign, IL: Human Kinetics.

Siedentop, D. (1981). The Ohio State University research program summary report. Journal of Teaching in Physical Education, 1, 3038.

Siedentop, D., \& Locke, L. (1997). Making a difference for physical education: What professors and practitioners must build together. Journal of Physical Education Recreation \& Dance, 64, 2533.

Simons, P. (1993). Constructivist learning: The role of the learner. In T. Duffy, J. Lowyck \& D. Jonassen (Eds.), Designing environments for constructivist learning (pp. 291313). London: Springer-Verlag.

Uebersax, J. (1992). A review of modeling approaches for the analysis of observer agreement. Investigative Radiology, 27, 738743. doi:10.1097/00004424-199209000-00017

Ward, P., \& Doutis, P. (1999). Toward a consolidation of the knowledge base for reform in physical education. Journal of Teaching in Physical Education, 18, 383402. 
Ward, P., Doutis, P., \& Evans, S. A. (1999). Lessons, conclusions, and implications of the SaberTooth project. Journal of Teaching in Physical Education, 18, 455463.

Warren Little, J. (2002). Locating learning in teachers' communities of practice: Opening up problems of analysis in records of everyday teaching work. Teaching and Teacher Education, 18, 917946. doi:10.1016/S0742-051X(02)00052-5

Webster-Wright, A. (2009). Reframing professional development through understanding authentic professional learning. Review of Educational Research, 79, 702739. doi:10.3102/00346543 08330970

Wentzel, K. (1991). Social competence at school: Relation between social responsibility and academic achievement. Review of Educational Research, 61, 124. doi:10.3102/003465430 61001001

Wright, P. M. (2012). Offering a TPSR physical activity club to adolescent boys labeled 'at risk' in a partnership with a community-based youth serving program. Agora for Physical Education \& Sport, 14, 94114. Retrieved from https://www5.uva.es/agora/revista/14_1/agora14_1g_wright.pdf

Wright, P. M., Li, W., Ding, S., \& Pickering, M. (2010). Integrating a personal and social responsibility program into a wellness course for urban high school students: Assessing implementation and educational outcomes. Sport, Education and Society, 15, 277298. doi:10.1080/13573322.2010.493309

Wright, P. M. (2009). Research on the teaching personal and social responsibility model: is it really in the margins? In L. Housner, M. Metzler, P. Schempp \& T. Templin (Eds.), Historic traditions and future directions on teaching and teacher education in physical education (pp. 290 296). Morgantown, WV: Fitness Information Technology.

Wright, P. M., \& Burton, S. (2008). Implementation and outcomes of a responsibility-based physical activity program integrated into an intact high school physical education class. Journal of Teaching in Physical Education, 27, 138154.

Wright, P. M., \& Craig, M. (2011). Tool for assessing responsibility-based education (TARE): Instrument development and reliability testing. Measurement in Physical Education and Exercise Science, 15, 204219. doi:10.1080/1091367X.2011.590084

Wright, P. M., \& Craig, M. (2009, April). Developing and reliability testing of a tool for assessing responsibility-based education. Paper presented at the American Alliance for Health, Physical Education, Recreation, and Dance, Tampa, Florida. 
